\title{
RECENT TRENDS IN THE MANAGEMENT OF SOFT TISSUE SARCOMAS
}

\author{
Mahalakshmi Ashokkumar1, Yeganathan Rajappan², Manimaran Thangavelu³, Anandan Kanthan4, Rajeswari Appanamuthumari ${ }^{5}$
}

${ }_{1}^{1}$ Assistant Professor, Department of General Surgery, KAPV Government Medical College, Trichy. 2 Associate Professor, Department of General Surgery, KAPV Government Medical College, Trichy. ${ }_{3}^{3}$ Assistant Professor, Department of General Surgery, KAPV Government Medical College, Trichy. 4 Postgraduate Student, Department of General Surgery, KAPV Government Medical College, Trichy. 5 Postgraduate Student, Department of General Surgery, KAPV Government Medical College, Trichy.

\section{ABSTRACT}

\section{BACKGROUND}

Soft tissue sarcomas are a heterogeneous group of tumours arising from primitive multipotent mesenchymal cells undergoing differentiation into one or more cell lines. They constitute $1 \%$ of human cancers. ${ }^{[1]}$ Most cases of soft tissue sarcoma are sporadic and the cause is unknown. Soft tissue sarcomas are one of the most common radiation associated tumours ${ }^{[2]}$ and they develop from any site and have more than 50 histological types and subtypes.

The aim of this study is to provide an overview of its distribution and to emphasise the recent trends in the management of soft tissue sarcoma with considerable change towards limb and organ saving attitude.[3]

\section{MATERIALS AND METHODS}

This study was conducted in KAPV Government Medical College and Mahatma Gandhi Memorial Government Hospital, Trichy between January 2014 and December 2016 over a period of 2 years. This study included 50 cases of soft tissue sarcoma, who were all inpatients in KAPV Government Medical College and Mahatma Gandhi Memorial Hospital, Trichy. Patients were descriptively studied for the distribution of soft tissue sarcoma and the mode of management adopted towards them.

\section{RESULTS}

The study shows the gender distribution of soft tissue sarcoma among 50 cases with 33 males (66\%) and 17 females (34\%). Among the 50 cases the incidence is higher in 51 - 60 years of age 10 cases (20\%), incidence is equal in 21 to 30 years and $31-40$ years' age group, both having 9 cases with $18 \%$ incidence. The lowest incidence is in above 70 years' age group, 1 case only (2\%). Lower limb is the site mostly affected with 20 cases (40\%). Upper limb and abdomen show equal numbers with 11 cases each $(22 \%)$ and lowest incidence is in gluteal site soft tissue sarcoma 1 case (2\%). Among the 14 types of soft tissue sarcoma studied, fibrosarcoma shows higher incidence with 17 cases (34\%) followed by malignant fibrous histiocytoma (MFH) 8 cases (16\%), chondrosarcoma, malignant haemangioendothelioma, GIST and spindle cell sarcoma have 1 case each (2\%). 27 cases were found to have stage 3 disease (54\%) and stage 4 disease among 3 cases (6\%). Regarding the treatment given, surgery alone was done in 3 cases (6\%). Surgery with chemotherapy and radiotherapy were done on 39 cases (78\%). Among the surgical procedures, wide local excision was done in 34 cases $(68 \%)$ and radical hysterectomy was done in 1 case $(2 \%)$. The recent trend in management of soft tissue sarcoma is towards organ saving attitude with the advent of multimodality approach. Surgery is the primary modality. Patients mostly underwent wide local excision and compartmental excision followed by postoperative radiotherapy and chemotherapy. Postoperative radiotherapy is given with external beam radiotherapy. Adjuvant chemotherapy was given with Vincristine, Adriamycin and Cyclophosphamide (VAC regimen). Out of 50 cases, 3 cases had recurrence in 2 years follow-up period.

\section{CONCLUSION}

Soft tissue sarcomas are rare tumours of mesenchymal origin. Multimodality approach in the management is the recent trend aimed at organ salvage. Surgery is the mainstay of management. Wide local excision and compartmental excision with postoperative adjuvant radiotherapy and chemotherapy gives good survival rates. Out of 50 cases only 3 cases had recurrence, thus showing the effectiveness of multimodality approach with surgery, radiotherapy and chemotherapy.

\section{KEYWORDS}

Soft Tissue Sarcoma, Wide Local Excision, Compartmental Excision, Amputation, Radiotherapy, Chemotherapy.

HOW TO CITE THIS ARTICLE: Ashokkumar M, Rajappan Y, Thangavelu M, et al. Recent trends in the management of soft tissue sarcomas. J. Evolution Med. Dent. Sci. 2018;7(01):43-46, DOI: 10.14260/jemds/2018/11

\section{BACKGROUND}

Soft tissue sarcoma are defined as heterogeneous group of tumours arising from primitive multipotent mesenchymal

'Financial or Other Competing Interest': None.

Submission 13-10-2017, Peer Review 10-12-2017,

Acceptance 19-12-2017, Published 01-01-2018.

Corresponding Author:

Dr. Yeganathan Rajappan,

Associate Professor, Department of General Surgery,

KAPV Government Medical College, Trichy.

E-mail: dryeganathan@gmail.com

DOI: $10.14260 /$ jemds/2018/11 cells undergoing differentiation into one or more lines. There are no clear predisposing factors. There are a wide variety of histological types according to the cell line of maturation with varying biological behaviour. Generally, these tumours do not cross anatomical barriers like bone, skin and fascia. Commonly spread by blood stream. They clinically present as painless lump. Diagnosis is established by tissue biopsy.[4] These tumours were approached aggressively with radical procedures like amputation twenty years back. The management of these tumours have undergone a radical change in the approach in the recent past due to better understanding of the tumour biology, advances in various 
fields of surgery like microvascular technique for flap coverage, availability of excellent chemotherapeutic agents and advances in radiotherapy.[5] With the availability of multimodality treatment, patients are benefitted with good quality of life with useful functioning limb or organ without compromise on the survival.[5] The aim of the study is to give an overview of the distribution of soft tissue sarcomas and to emphasise the recent trend in the management of soft tissue sarcoma with considerable change towards limb and organ saving attitude.

\section{MATERIALS AND METHODS \\ Study Place}

KAPV Government Medical College and Mahatma Gandhi Memorial Hospital, Trichy.

\section{Duration of Study}

January 2014 to December 2016.

\section{Study Design}

Descriptive Study.

\section{Ethical Committee}

Institutional Ethical Committee, KAPV Government Medical College, approved in January 2014.

\section{Inclusion Criteria}

Patients aged above 12 years. All sex group patients who were confirmed with soft tissue sarcoma.

\section{Exclusion Criteria}

Patients aged less than 12 years. Patients not confirmed with soft tissue sarcoma through Tru-cut biopsy.

\section{Data Collection and Methods}

Patients confirmed with soft tissue sarcoma in Mahatma Gandhi Memorial Government Hospital, Trichy, were included in the study. Details of patients with soft tissue sarcoma and their histological types were identified. Among the many types of soft tissue sarcoma, fourteen histological types that were available were studied descriptively. I have selected 50 cases of soft tissue sarcoma with 14 histological types who were admitted in Mahatma Gandhi Memorial Government Hospital, Trichy, between January 2014 and December 2016. They were managed with-1. Surgery alone, 2. Surgery with radiotherapy and 3. Surgery with radiotherapy and chemotherapy. Surgical methods employed were Wide Local Excision, Compartmental Excision, Amputation, Resection anastomosis, Radical hysterectomy and Lymph node dissection. Postoperative histopathological reports were obtained and adjuvant treatment with radiotherapy or with chemotherapy and radiotherapy were advised. Patients were followed up for a period of two years. In the follow-up period of the 50 cases, 3 patients had recurrence. Among the three cases, one case did not turn up for further follow-up.

\section{Statistical Analysis}

Descriptive statistics such as frequency and proportion were calculated.

\section{RESULTS}

50 patients with soft tissue tumour appearing malignant were studied.

\begin{tabular}{|c|c|c|}
\hline Gender & No. of Patients & Percentage \\
\hline Male & 33 & $66 \%$ \\
\hline Female & 17 & $34 \%$ \\
\hline Total & $\mathbf{5 0}$ & $\mathbf{1 0 0 \%}$ \\
\hline \multicolumn{2}{|c|}{ Table 1. Gender Distribution } \\
\hline
\end{tabular}

\begin{tabular}{|c|c|c|}
\hline Age & Total & Percentage \\
\hline $13-20$ & 8 & $16 \%$ \\
\hline $21-30$ & 9 & $18 \%$ \\
\hline $31-40$ & 9 & $18 \%$ \\
\hline $41-50$ & 8 & $16 \%$ \\
\hline $51-60$ & 10 & $20 \%$ \\
\hline $61-70$ & 5 & $10 \%$ \\
\hline Above 70 & 1 & $2 \%$ \\
\hline Total & 50 & 100 \\
\hline \multicolumn{3}{|c|}{ Table 2. Distribution according to Age } \\
\hline
\end{tabular}

\begin{tabular}{|c|c|c|}
\hline Site & Total & Percentage \\
\hline Lower Limb & 16 & $32 \%$ \\
Thigh & 3 & $6 \%$ \\
Leg & 1 & $2 \%$ \\
Foot & & \\
\hline Upper Limb & 4 & $8 \%$ \\
Hand & 3 & $6 \%$ \\
Forearm & 4 & $8 \%$ \\
Arm & 4 & $8 \%$ \\
Abdomen & 3 & $6 \%$ \\
Abdominal wall & 4 & $8 \%$ \\
Intraperitoneal & 1 & $2 \%$ \\
Retroperitoneal & 3 & $6 \%$ \\
\hline Gluteal Region & 4 & $8 \%$ \\
\hline \multicolumn{2}{|c|}{ Chest Wall } & \\
\hline Hand and Neck & \multicolumn{2}{|c|}{ Table 3. Distribution according to Site } \\
\hline \multicolumn{2}{|c|}{}
\end{tabular}

\begin{tabular}{|c|c|c|c|c|}
\hline HPE & Male & Female & Total & $\%$ \\
\hline Fibrosarcoma & 10 & 7 & 17 & $34 \%$ \\
\hline MFH & 5 & 3 & 8 & $16 \%$ \\
\hline Liposarcoma & 2 & 3 & 5 & $10 \%$ \\
\hline $\begin{array}{l}\text { Dermatofibrosarcoma } \\
\text { protuberans }\end{array}$ & 3 & - & 3 & $6 \%$ \\
\hline Synovial sarcoma & 2 & 1 & 3 & $6 \%$ \\
\hline Leiomyosarcoma & 1 & 1 & 2 & $4 \%$ \\
\hline Haemangiopericytoma & - & 2 & 2 & $4 \%$ \\
\hline Malignant schwannoma & 1 & 1 & 2 & $4 \%$ \\
\hline MPSNT & 2 & - & 2 & $4 \%$ \\
\hline Desmoid tumour & 1 & 1 & 2 & $4 \%$ \\
\hline Chondrosarcoma & 1 & - & 1 & $2 \%$ \\
\hline $\begin{array}{c}\text { Malignant } \\
\text { haemangioendothelioma }\end{array}$ & - & 1 & 1 & $2 \%$ \\
\hline GIST & 1 & - & 1 & $2 \%$ \\
\hline Spindle cell sarcoma & 1 & - & 1 & $2 \%$ \\
\hline \multicolumn{5}{|c|}{$\begin{array}{c}\text { Table 4. Distribution according to the } \\
\text { Histopathology Subtype }{ }^{[7],[8]}\end{array}$} \\
\hline
\end{tabular}




\begin{tabular}{|c|c|c|}
\hline Stage & No. of Patients & Percentage \\
\hline Stage- 1 & 4 & $8 \%$ \\
\hline Stage- 2 & 16 & $32 \%$ \\
\hline Stage- 3 & 27 & $54 \%$ \\
\hline Stage- 4 & 3 & $6 \%$ \\
\hline \multicolumn{2}{|c|}{ Table 5. Distribution according to the Stage of Disease } \\
\hline
\end{tabular}

\begin{tabular}{|c|c|c|}
\hline Modality of Treatment & No. of Patients & Percentage \\
\hline Surgery alone & 3 & $6 \%$ \\
\hline Surgery + RT & 8 & $16 \%$ \\
\hline Surgery + RT + ChT & 39 & $78 \%$ \\
\hline Total & 50 & $100 \%$ \\
\hline \multicolumn{3}{|c|}{ Table 6. Modality of Treatment } \\
\hline
\end{tabular}

\begin{tabular}{|c|c|c|}
\hline Detail of Surgery & No. of Patients & Percentage \\
\hline Wide Local Excision & 34 & $68 \%$ \\
\hline Compartmental Excision & 4 & $8 \%$ \\
\hline Amputation & 6 & $12 \%$ \\
\hline Resection Anastomosis & 20 & $4 \%$ \\
\hline Radical Hysterectomy & 1 & $2 \%$ \\
\hline Lymph Node Dissection & 3 & $6 \%$ \\
\hline \multicolumn{2}{|c|}{ Table 7. Distribution of Patients among various } \\
Surgical Procedures \\
\hline
\end{tabular}

\section{DISCUSSION}

As per literature, benign soft tissue tumours outnumber malignant ones which are rare tumours.[6] Incidence is $1 \%$ $2 \%$. Soft tissue tumours present clinically as painless mass growing over a period of months. Incidence in males is more when compared to females. Extremity sarcomas are common.[7] Fibrosarcomas and malignant fibrous histiocytomas are more common than other histological variety. Patients usually present in stage II or III disease. Metastatic sarcomas do occur in lesser number. Patients were subjected to core needle biopsy for confirmation of diagnosis and grading of tumour. FNAC is useful in recurrent soft tissue sarcomas. These tumours were treated radically with amputation of limb 20 years back. The recent trend in the management of soft tissue sarcomas is towards limb saving, organ saving attitude with the advent of multimodality approach. Surgery is the primary modality of treatment. Post excisional defects were reconstructed with skin graft and myocutaneous flaps with the availability of microvascular technique with good cosmetic results in functioning limb. Patients usually underwent wide local excision and compartmental excision followed by postoperative radiotherapy to the tumour bed and chemotherapy.[8] The results are comparable with that of amputation practiced previously. Postoperative radiotherapy was given as external radiotherapy of 50 grey given as 200 cgy per day for 5 days per week for 5 weeks. Adjuvant chemotherapy was given with combination chemotherapy using VAC regimen (Vincristine, Adriamycin and Cyclophosphamide).[9] Doxorubicin and Ifosfamide was also used in some patients with comparable results. Neoadjuvant chemotherapy or radiotherapy to downstage the disease is not practiced for soft tissue tumours in contrast to bone sarcomas. Isolated limb perfusion technique was not undertaken due to nonavailability of technology in our institution. Out of 50 patients only 3 patients had recurrence in the 2-year follow-up period, possibly due to aggressiveness of high-grade tumours. Patients who presented with metastatic tumours were treated with palliative chemotherapy with palliative resection of primary tumour including amputation. Of the three, one was lost for followup and one died of pulmonary metastasis.

\section{CONCLUSION}

Soft tissue sarcomas are rare tumours of mesenchymal origin, presents as painless mass. Extremity sarcomas are common. Diagnosed by core needle or incisional biopsy. Multimodality approach in the management is the recent trend, aiming at limb or organ salvage. Surgery is the mainstay of management. Wide local excision and compartmental excision with postop adjuvant radiotherapy and combination chemotherapy results in good survival rates with adequate limb salvage. Targeted therapy as for GIST with tyrosine kinase inhibitor Imatinib gives promising results. Gene therapy, monoclonal antibodies and angiogenesis inhibitors may play a crucial role in the management of soft tissue sarcoma aiming better survival rate or even cure.

\section{ACKNOWLEDGEMENTS}

I thank the Dean of KAPV Government Medical College and Mahatma Gandhi Memorial Government Hospital, Trichy, Professor Dr. Muralidharan MS, M.Ch, for permitting me to conduct the study in the Department of General Surgery of KAPV Government Medical College and Mahatma Gandhi Memorial Government Hospital, Trichy. I thank Professor Dr. Thulasi MS, DGO, Head of Department of General Surgery and my Unit Chief Associate Professor Dr. R. Yeganathan MS, DA for helping and guiding me through this study. I am thankful to my colleague Assistant Professor Dr. T. Manimaran MS and my postgraduate students Dr. K. Anandan, Dr. A. M. Rajeshwari and Dr. K. Swathika for helping me in this study. My gratitude to the Professors and Assistant Professors of all other units. I am thankful to all my patients for successful completion of the study.

\section{REFERENCES}

[1] Jemal A, Siegel R, Ward E, et al. Cancer statistics, 2009. CA Cancer J Clin 2009;59(4):225-49.

[2] Kirova YM, Gambotti L, De Rycke Y, et al. Risk of second malignancies after adjuvant Radiotherapy for breast cancer: a large-scale, single-institution review. Int J Radiat Oncol Biol Phys 2007;68(2):359-63.

[3] Baldini EH, Goldberg J, Jenner C, et al. Long-term outcome after function-sparing surgery without radiotherapy for soft tissue sarcoma of extremities and trunk. J Clin Oncol 1999;17(10):3252-9.

[4] Clark MA, Fisher C, Judson L, et al. Soft tissue sarcomas in adults. N Eng J Med 2005;353(7):701-11.

[5] Pisters PW, Pollock RE, Lewiss VO, et al. Long-term trial of prospective results of surgery alone with selective use of radiation for patients with T1 extremity and trunk soft tissue sarcomas. Ann Surg 2007;246(4):675-82.

[6] American cancer society, cancer facts and figure 2016. Atlanta, Ga, American cancer society, 2016

[7] Pisters PW, Leung DH, Woodruff J, et al. Analysis of prognostic factors in 1,041 patients with localised soft tissue sarcomas of the extremities. J Clin Oncol 1996;14(5):1679-89. 
[8] Rosenberg SA, Tepper J, Glatstein E, et al. The treatment of soft tissue sarcomas of extremities: prospective randomised evaluation of (1) limbsparing surgery plus radiation therapy compared with amputation and (2) the role of adjuvant chemotherapy. Ann Surg 1982;196(3):305-15.
[9] Sarcoma meta-analysis collaboration. Adjuvant chemotherapy for localised resectable soft-tissue sarcoma of adults: meta-analysis of individual data. Lancet 1997;350(9092):1647-54. 